\title{
Physicochemical Properties of Rhamnolipid Biosurfactant from Pseudomonas aeruginosa PA1 to Applications in Microemulsions
}

\author{
Anderson Nogueira Mendes,2, Lívia Alves Filgueiras', José Carlos Pinto², Marcio Nele \\ ${ }^{1}$ Departamento de Biofisica e Fisiologia, Universidade Federal do Piauí, Teresina, Brazil \\ ${ }^{2}$ Programa de Engenharia Química, Instituto de Tecnologia, Universidade Federal do Rio de Janeiro, Rio de \\ Janeiro, Brazil \\ ${ }^{3}$ Departamento de Engenharia Química, Escola de Química, Universidade Federal do Rio de Janeiro, Rio de \\ Janeiro, Brazil \\ Email: nele@eq.ufri.br
}

Received 25 December 2014; accepted 14 January 2015; published 21 January 2015

Copyright (C) 2015 by authors and Scientific Research Publishing Inc.

This work is licensed under the Creative Commons Attribution International License (CC BY).

http://creativecommons.org/licenses/by/4.0/

(c) $\underset{\mathrm{EY}}{\mathrm{P}}$ Open Access

\begin{abstract}
Interfacial properties rhamnolipids from an extract produced by a strain of Pseudomonas aeruginosa were analyzed in this study. The extract of rhamnolipid was characterized by surface tension in different conditions; interfacial tension with different hydrocarbons; critical micelle concentration under different $\mathrm{pH}$ and temperatures; particle size and emulsification capacity using laser light profiling. It was observed that the rhamnolipids extract are sensitive to variations in $\mathrm{pH}$, thermostable and function as good emulsificant for emulsification of methyl methacrylate. The emulsion stability order in function of the oil phase was methyl methacrylate $>$ emulsions of castor oil > emulsion n-heptane > emulsion toluene $>$ emulsion hexadecane $>$ octane emulsion. The data presented show that rhamnolipid extracts may be used to formulate stable emulsions of methyl methacrylate. This process can be used to do nano/microsphere of polymethyl methacrylate.
\end{abstract}

\section{Keywords}

Rhamnolipids, Surface Tension, Emulsion Stability, Microemulsions

\section{Introduction}

Rhamnolipids are amphiphilic molecules composed of a hydrophobic fatty acid moiety (with C8-C14 carbon atoms, which may or may not be saturated) and a hydrophilic portion composed of one or two rhamnose residue 
[1]-[5]. Pseudomonas strain can produces 28 different rhamnolipids homologues from different carbon sources [6].

The presence of others minor rhamnolipids homologues involving C8, C10, C12, and C14 3-hydroxy fatty acids have been described in the literature [5]-[8]. The composition of rhamnolipids produced by Pseudomonas is related to many parameters, the most importantly being: strain, media composition, culture conditions, and culture age [1] [5] [8] [9]. Pseudomonas aeruginosa CCTCC AB93066, for example, produces two groups of monorhamnolipid and dirhamnolipid in aerobic fermentation [10]. They are RhaC10C10, RhaC10C12-H2, RhaC10C12 for monorhamnolipid and Rha2C10C10, Rha2C10C12-H2, Rha2C10C12 for dirhamnolipid [10]. The resulting mixture of homologues determines the property of the biosurfactant, and even slight differences in the mixture composition can have significant consequences for physic-chemical properties of the surfactant [5]. These properties have several potential industrial and environmental applications that include the production of chemicals, surface coating, additives for environmental remediation, as well as being useful biological control agents [2]-[4].

Several recent studies on rhamnolipids were focused on their adsorption, aggregation, and micellization properties, which are also the important parameters for estimating surfactant in process of solubilization, suspension, and dispersion [11]. Further investigation of the surface activity and other physico-chemical properties is necessary to better understand the behavior of rhamnolipids in emulsions and other industrial or environmental applications.

In fact, surface properties and micellization behavior of a single chemical and separated rhamnolipid, or even rhamnolipidic crude mixture, were reported to be variable [9] [11] [12]. In environmental remediation, the composition of the rhamnolipid mixture and the resulting features may influence its capability to enhance contaminants bioavailability and transport [8] [12] [13]. For example, di-rhamnolipids were described in the literature as biosurfactants that have a lower capacity of micellar solubilization of phenanthrene than mono-rhamnolipids, but di-rhamnolipids showed a greater enhancement in bioavailability of the micellized contaminant [12]-[15]. Biosurfactants in solution, with high surface and interfacial tension reduction capabilities, can facilitate the transport of sorbed pollutants in soil [12] [13]. For a successful practical application of rhamnolipid mixtures produced in batch culture of Pseudomonas, it is necessary to investigate their physicochemical properties.

In this study, a rhamnolipid mixture was produced by the P. aeruginosa strain PA1 and then isolated by partitioning with chloroform-ethanol. The composition of the rhamnolipid mixture was chemically characterized, and the interfacial properties and micellization behavior were comparatively investigated. The analysis of the data shown in this article can provide a better understanding of the functions, characteristics and behavior of mixtures of rhamnolipids for use in polymerization processes, biochemical processes, and pharmaceutical and environmental remediation.

\section{Materials and Methods}

\subsection{Rhamnolipid Production}

Pseudomonas aeruginosa PA1 was inoculated in Erlenmeyer flasks containing $600 \mathrm{~mL}$ of culture medium $\left(\mathrm{NaNO}_{3} 1.0 \mathrm{~g} / \mathrm{L} ; \mathrm{KH}_{2} \mathrm{PO}_{4} 3.0 \mathrm{~g} / \mathrm{L} ; \mathrm{K}_{2} \mathrm{HPO}_{4} 7.0 \mathrm{~g} / \mathrm{L} ; \mathrm{MgSO}_{4} \cdot 7 \mathrm{H}_{2} \mathrm{O} 0.2 \mathrm{~g} / \mathrm{L} ; 0.5 \%\right.$ yeast extract; peptone $0.5 \%$ and $3 \%$ glycerol). The Erlenmeyers were placed in a rotary shaker at $170 \mathrm{rpm}$ for 24 hours, at $30^{\circ} \mathrm{C}$. The cell culture was centrifuged (10,000 g, 30 minutes) and then dispersed again in distilled water. The cells were then centrifuged, recovered and used as inoculums [16]. These inoculums were added to a $2 \mathrm{~L}$ Erlenmeyer flask containing $1.2 \mathrm{~L}$ of production medium (glycerol 3\%; $\mathrm{NaNO}_{3} 1.0 \mathrm{~g} / \mathrm{L} ; \mathrm{KH}_{2} \mathrm{PO}_{4} 3.0 \mathrm{~g} / \mathrm{L} \mathrm{K} \mathrm{K}_{2} \mathrm{HPO}_{4} 7.0 \mathrm{~g} / \mathrm{L}$; $\mathrm{MgSO}_{4} \cdot 7 \mathrm{H}_{2} \mathrm{O} 0.2 \mathrm{~g} / \mathrm{L}$ ). They were then incubated at $30^{\circ} \mathrm{C}$ at $170 \mathrm{rpm}$ for 168 hours. Every 24 hours, $1.5 \mathrm{~mL}$ aliquots were taken for analysis of cell growth and rhamnolipid concentration [16] [17].

The cell concentration in the suspension of $P$. aeruginosa was calculated as dry mass (PS) (g/L), by measuring the absorbance at $600 \mathrm{~nm}$ and using a calibration curve of dry weight (ABS PS $=1.2595(\mathrm{~g} / \mathrm{L})-\mathrm{R} 2=0.989)$. To determine the concentration of rhamnolipids, the method described by Dubois et al. was used [18].

\subsection{Rhamnolipid Extraction}

The cells were separated by centrifugation of the culture medium at $10,000 \times \mathrm{g}$ for 20 minutes and autoclaved. The culture medium, free of cells, containing the biosurfactant was subjected to a reverse osmosis process for 
concentration by water removal using a reverse osmosis system containing $\mathrm{N}_{2}$ at a constant pressure of 300 psi $\left(20 \mathrm{kgf} / \mathrm{cm}^{2}\right)$, a reverse osmosis membrane (model: BW30-2540-DOW FILMTEC) and a magnetic stirring system. Rhamnolipid purification was carried out by extraction, using a chloroform/methanol/culture medium mixture, in the proportion of 2:1:1 and a separating funnel (see Figure 1). The organic chloroform rich phase was separated, the solvent evaporated a pasty product with a brownish color [17] was obtained.

\subsection{Surface and Interfacial Tension Measurements}

The surface tension measurements were carried on a tensiometer Krüss K100 using the Wilhelmy plate method. The rhamnolipids rich extract (RLe) was diluted in deionized water at a concentration of $0.15 \mathrm{~g} / \mathrm{L}$. The samples were then analyzed for 20 minutes at each temperature of $4^{\circ} \mathrm{C}, 25^{\circ} \mathrm{C}, 60^{\circ} \mathrm{C}$ and $80^{\circ} \mathrm{C}$, then cooled from $80^{\circ} \mathrm{C}$ to $4^{\circ} \mathrm{C}$ following the same path. The sample was stored in the refrigerator and analyzed again in the following day.

To measure the surface tension at different $\mathrm{pH}$, the rhamnolpid extract was diluted in $1 \mathrm{~g} / \mathrm{L}$ with water deionized with different $\mathrm{pH}$ : alkaline medium $(\mathrm{pH}=10.8)$, adjusted with a $1 \mathrm{M} \mathrm{NaOH}$ or $\mathrm{KOH}$ solutions; acid medium $(\mathrm{pH}=3.4)$, adjusted with a $1 \mathrm{M} \mathrm{HCl}$ solution; and without any adjustment of $\mathrm{pH}$ ( $\mathrm{pH}$ about 6.3). During the whole titration process, the $\mathrm{pH}$ value was monitored.

The interfacial tension analyses were performed in DSA100 tensiometer, using the pendant drop method. The data were analyzed using the software Drop Shape Analysis System DSA100. The interfacial tension between water (with and without the extract of rhamnolipids) and different hydrocarbons was measured at room temperature $\left(25^{\circ} \mathrm{C}\right)$.

\subsection{Zeta Potential and Aggregate Size Measurements}

The zeta potential and particle size was measured on a Nano ZS-Malvern Instruments equipment. Rhamnolipids extract solutions were prepared at $\mathrm{pH} 3.4,10.8$ and 6.3 at different concentrations at a concentration of $5 \mathrm{~g} / \mathrm{L}$. The samples were pre-filtered in a $0.45 \mu \mathrm{m}$ membrane filter and added to a cuvette for measurements.

\subsection{Emulsion Stability}

The emulsion stability was analyzed at room temperature by laser profiling using the Turbiscan TLAB from Formulaction ${ }^{\circledR}$. This technique allows the scanning of transmitted and scattered light of flasks containing emulsions or suspensions in various positions along the sample height. The measurement result is the light transmission and backscattering profile from the sample in function of the height of the tube (mm), from the bottom to the top of the tube [19].

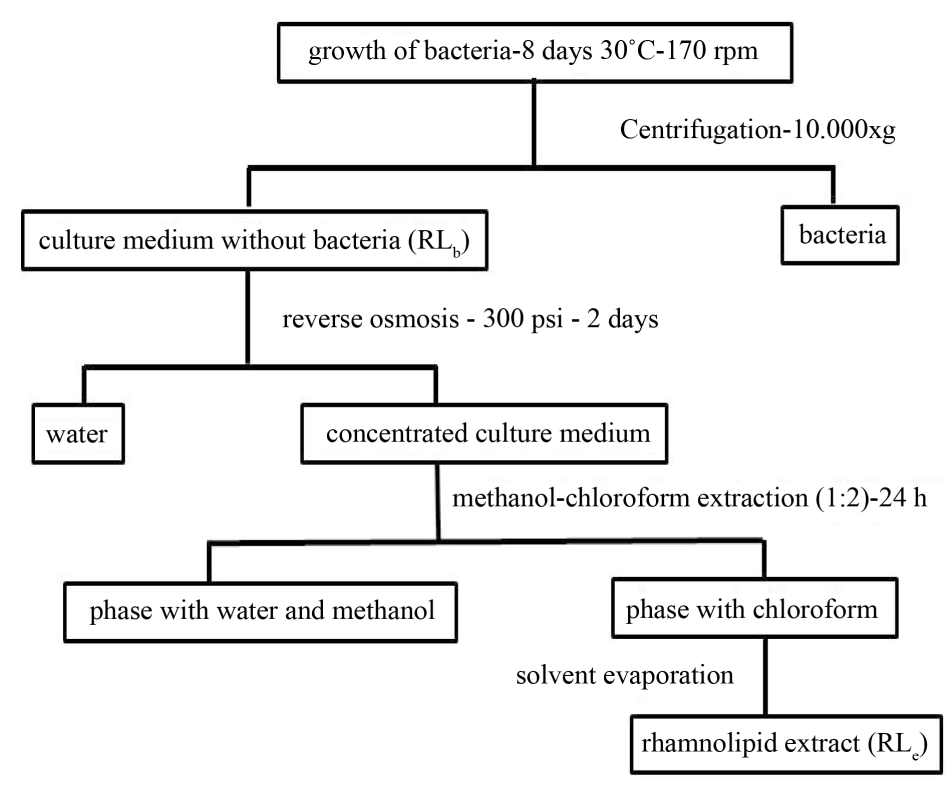

Figure 1. Summary of procedure to obtain the rhamnolipid rich extract. 
The emulsions were prepared by mixing 50\% water rhamnolipid solution $(150 \mathrm{mg} / \mathrm{L})$ and $50 \%$ of hydrocarbon (w/w). The samples were sonicated by an ultrasound probe (Sonics model VCX750) for 4 minutes with amplitude of $40 \%$. Then, $20 \mathrm{ml}$ of sample was added into a flask for analysis of the stability of the emulsion in the Turbiscan TLAB.

\section{Results and Discussion}

A comparison of the surface tension of solutions (culture medium RLb and rhamnolipid extract RLe at different concentrations) shows that the rhamnolipid extract (RLe) reduces the surface tension of water at a lower concentration than RLb, as expected by an increase in the rhamnolipid concentration due to the purification process. At the same time the CMC of the RLb and $198.1 \mathrm{mg} / \mathrm{L}$ while of the RLe is $25.7 \mathrm{mg} / \mathrm{L}$, resulting in a difference of almost eight times (Figure 2), comparatively the CMC of SDS measured was $2.6 \mathrm{~g} / \mathrm{L}$, and according to the literature, the critical micelle concentration of SDS is $0.00835 \mathrm{~mol} / \mathrm{L}(2.56 \mathrm{~g} / \mathrm{L})$ [20].

The SDS reduced the surface tension less than the rhamnolipid ( $\sim 27 \mathrm{mN} / \mathrm{m}$-rhamnolipids against $\sim 36 \mathrm{mN} / \mathrm{m}-$ SDS). Interestingly, it is only required about $2.6 \mathrm{~g}$ of SDS, compared to $26 \mathrm{mg}$ of RLe (value 100 times smaller), to achieve CMC. This shows that in relation to surface tension reduction, rhamnolipids are more effective and have a much larger molecular area at air/liquid interface.

Industrial applications, such as surfactant in polymerization reaction, require surfactant thermal stability at up to $80^{\circ} \mathrm{C}$. Many surfactants are sensitive to temperature, thus, RLe solutions were heated and cooled to assess thermal stability (Figure 3). A solution of RLe at a concentration 6 times the value of CMC (150 mg/L) was used during this process. The solution was heated to $80^{\circ} \mathrm{C}$ and then cooled to $4^{\circ} \mathrm{C}$, and the surface tension was measured at $4^{\circ} \mathrm{C}, 25^{\circ} \mathrm{C}, 60^{\circ} \mathrm{C}$ and $80^{\circ} \mathrm{C}$. The process was repeated on the same sample the following day (Figure 3). The rhamnolipids proved to be thermoresistant to a temperature up $80^{\circ} \mathrm{C}$.

Environmental factor such as $\mathrm{pH}$, salinity and temperature play a crucial role in influencing the effectiveness of rhamnolipids [21] [22]. Ilori et al., (2005) demonstrated that the chemical structure of biosurfactants gives an advantage to the degradation of hydrocarbons, but it can probably be destroyed under extreme conditions of temperature and $\mathrm{pH}$ [22]. This advantage is associated with a decreased interfacial tension between polar and nonpolar liquids, which can increase the availability of hydrocarbons in water for different bacteria to grow.

Many surfactants can tolerate extremes $\mathrm{pH}$, but rhamnolipids are sensitive to $\mathrm{pH}$ changes, the variation of surface tension under different $\mathrm{pH}$ is shown in Figure 4. Critical micelle concentration is sensitive to $\mathrm{pH}$, therefore the variation of $\mathrm{pH}$ changes the ability of the biosurfactant to form micelles or to adsorb on the interface. As Figure 4 shows, when the mixture is alkalized with $\mathrm{NaOH}$ or $\mathrm{KOH}$ solutions to a $\mathrm{pH}$ of 10.8 there is a negligible change in surface tension curve.

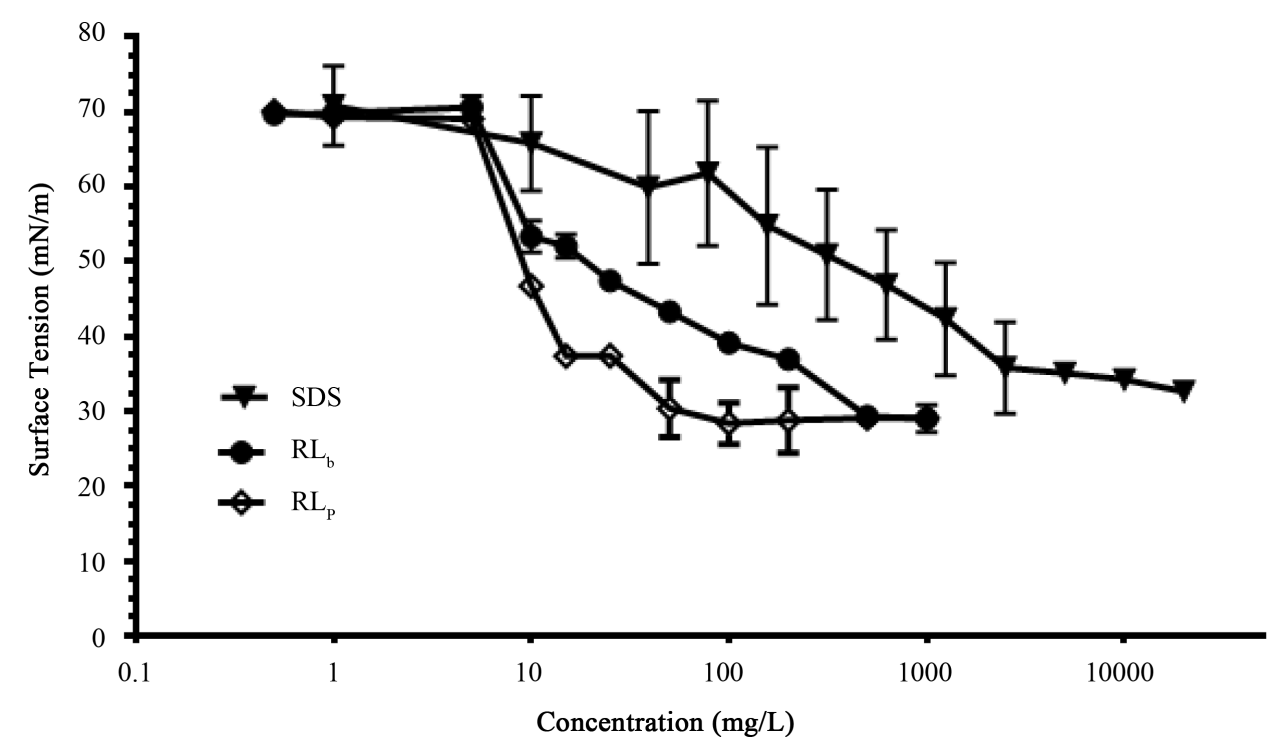

Figure 2. Surface tension comparison of the culture medium free of bacteria (RLb), rhamnolipid extract (RLe) and sodium dodecil sulfate (SDS) at different concentrations. 


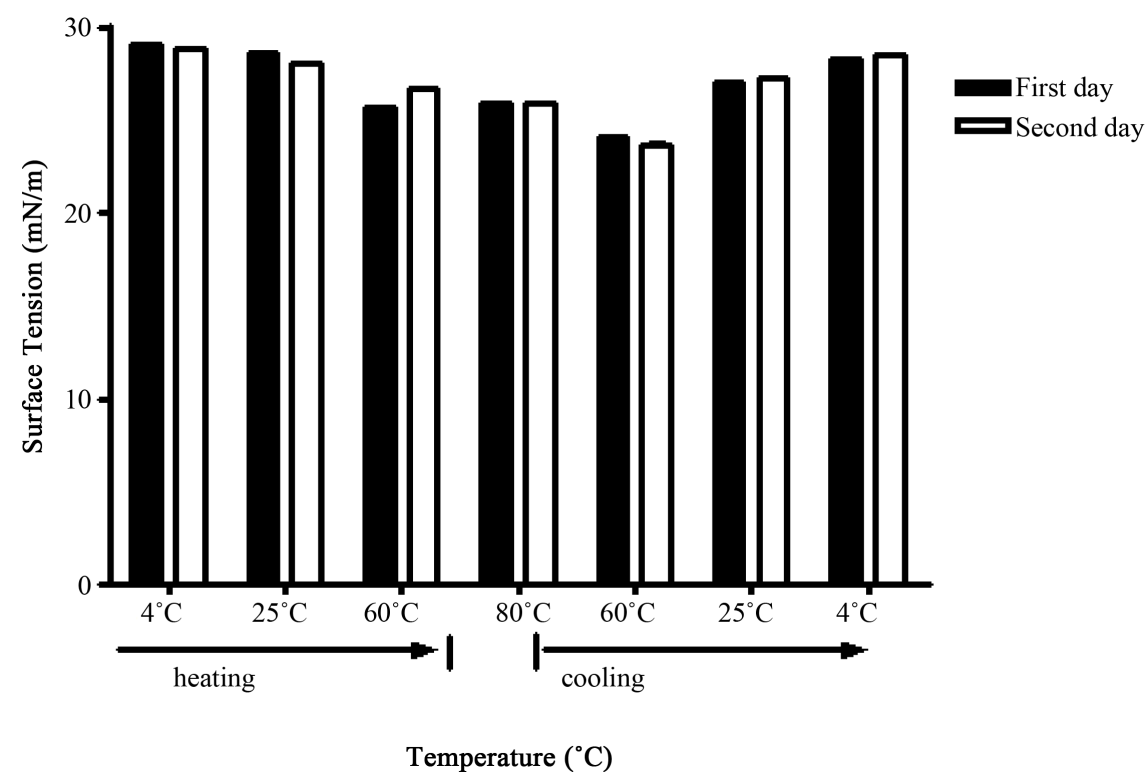

Figure 3. Analysis of the surface tension of a $150 \mathrm{mg} / \mathrm{L}$ RLe solution in water during the heating and cooling.

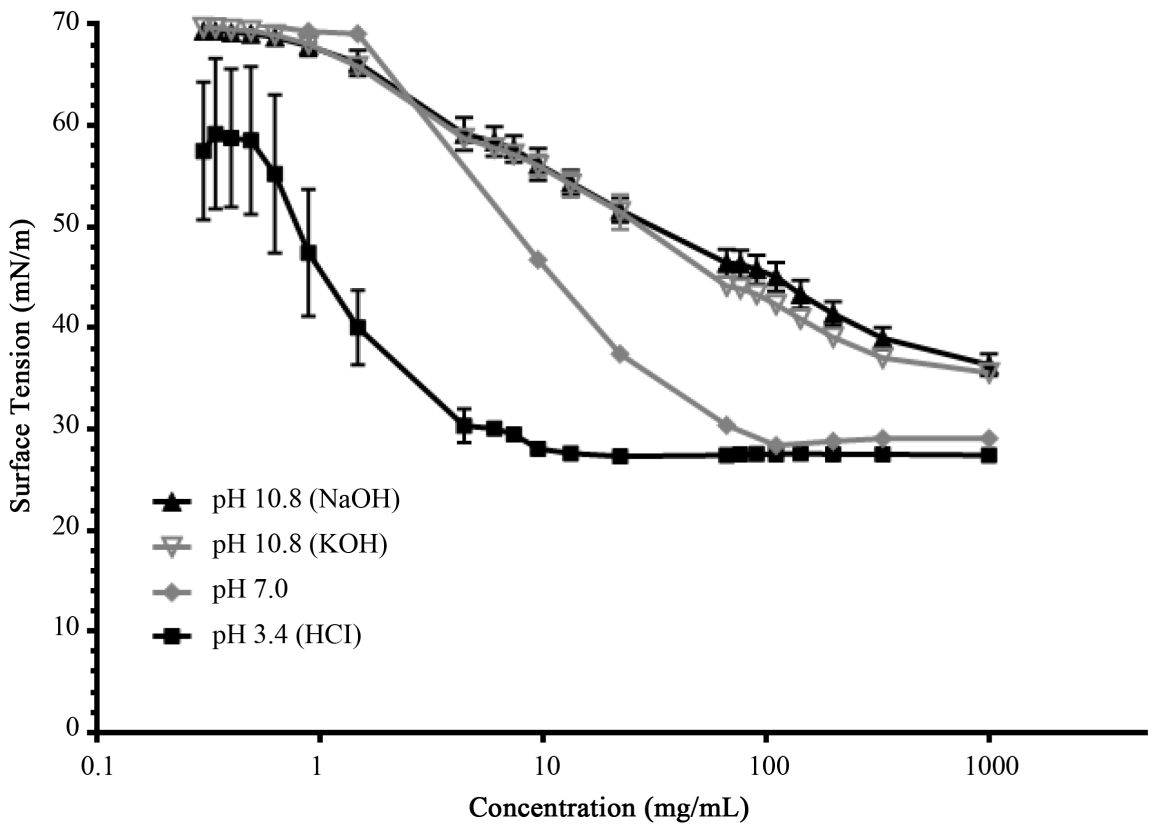

Figure 4. Evaluation of RLe solutions surface tension at different $\mathrm{pH}$..

According to Lebrón-Paler et al. (2006), rhamnolipids are weak acids due to the presence of the carboxylic acid moiety, known to undergo aggregation in solution and to have a pKa of about 5.6 [23]. If there is a variation in $\mathrm{pH}$, in values below 5.6 or above the rhamnolipids can undergo intrinsic change in load, or loss by dissociation of $\mathrm{H}^{+}$[23]. Changes in $\mathrm{pH}$ can influence the variation of rhamnolipids CMC [1] [3] [5] [23] [24].

A similar result, with different concentrations of di-rhamnolipids, was reported by Sánchez et al. [25]. In his study a concentration-dependent micelles-vesicle transition was determined. By surface tension measurements, they demonstrated that at $\mathrm{pH} 7.4$ the CMC of dirhamnolipid is $0.110 \mathrm{mM}$, whereas at $\mathrm{pH} 4.0$ it falls to 0.010 $\mathrm{mM}$. This indicates that a negatively charged dirhamnolipid has a much higher CMC value than the neutral species [25]. 
At concentrations above the CMC, rhamnolipids form micelles, vesicles, or lamella depending on the solution $\mathrm{pH}$, concentration, and presence of electrolytes [1] [3] [5] [13] [23] [26]. Changes in micellar structure of rhamnolipids may be a consequence of altering the intrinsic charge of the molecule or modification of the micelle charge.

The micelles or bi-layers formed by self assembly of surfactants in CMC may also aggregate and generate vesicles in aqueous solution as bulk [5]. Spherical surfactant vesicles of various sizes (50 - $250 \mathrm{~nm}$ ) are spontaneously formed at a rhamnolipid concentration greater than its critical micelle concentration (CMC), which was $200 \mathrm{mg} / \mathrm{L}$ [26] [27].

The variation of $\mathrm{pH}$ is an important factor to increase or decrease the stability of emulsions with rhamnolipids [28]. The carboxylic moiety of rhamnolipids executes the functional control of the amphipathic properties of rhamnolipids, depending on the environmental $\mathrm{pH}$ and on the concentration of rhamnolipids, which is mild for biomembranes [29]-[31]. The change in pH modifies the IFT result because the carboxylate group pKa leads to a partial dissociation [32]. With lower $\mathrm{pH}$, more of the biosurfactant is in acid form.

Analysis of zeta potential and particle size can help to understand the behavior of rhamnolipids in solutions (Figure 5 and Figure 6). To examine the variation of micelle or vesicles size, a series of measurements using DLS (Dynamic Light Scattering) sizer was carried out at concentrations above CMC (pH dependent) at different conditions.

A significant proportion of large aggregates (distribution mode about $200 \mathrm{~nm}$ ) was found in all pHs indicating the formation of aggregates with relatively large hydrodynamic radius. At $\mathrm{pH} 10.8$, a size distribution mode about $7 \mathrm{~nm}$ was observed, suggesting that when the rhamnolipid is in the charged state electrostatic repulsion existing between headgroups leads to small micelles. This confirms that micelle growth, due to the intermolecular or intermicellar aggregation, or aggregate shape transition may occurs when a change of $\mathrm{pH}$ (or concentration) in the bulk happen.

The previous experiments were important to demonstrate the effects of various parameters, such as: temperature, $\mathrm{pH}$ and salts in the properties of solutions containing the extract RLe. Previous works demonstrate the ability of rhamnolipids to reduce aqueous surface tension [1]-[7] [21]-[28]. However, there is still the need to characterize the behavior of this surfactant in the oil/water interface. Thus, experiments were performed to evaluate interfacial tension between oil and water (with or without RLe) and to contribute to the characterization of the surfactant behavior (Table 1). Table 1 shows the interfacial tension between hydrocarbon and rhamnolipid water solutions. At a concentration of $0.15 \mathrm{~g} / \mathrm{L}$ of RLe, there was a significant reduction in the interfacial tension between: toluene and water of $33 \mathrm{mN} / \mathrm{m}$ for $3 \mathrm{mN} / \mathrm{m}$, n-heptane and water $43 \mathrm{mN} / \mathrm{m}$ for $3 \mathrm{mN} / \mathrm{m}$; octane and water $47 \mathrm{mN} / \mathrm{m}$ for $1 \mathrm{mN} / \mathrm{m}$; hexadecane and water $49 \mathrm{mN} / \mathrm{m}$ for $1 \mathrm{mN} / \mathrm{m}$.

These results demonstrate that RLe can reduce the interfacial tension between water and hydrocarbons with

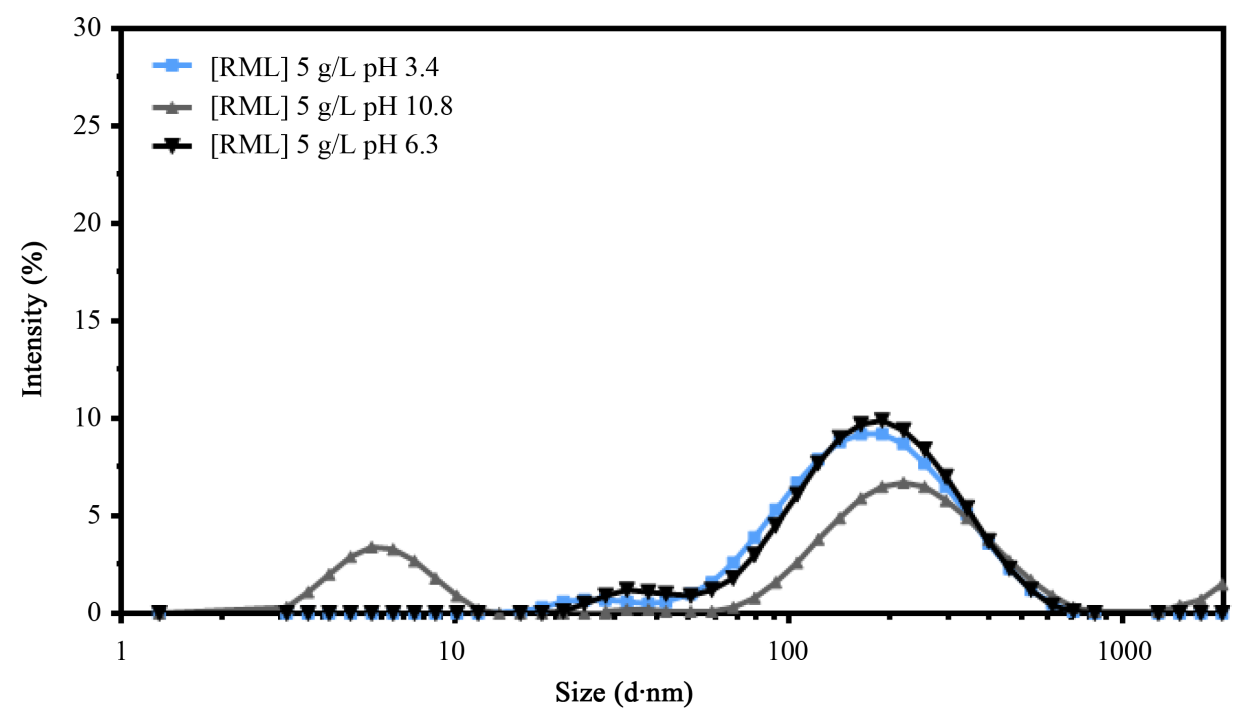

Figure 5. Aggregate size distribution of rhamnopilid solution at different pHs. 


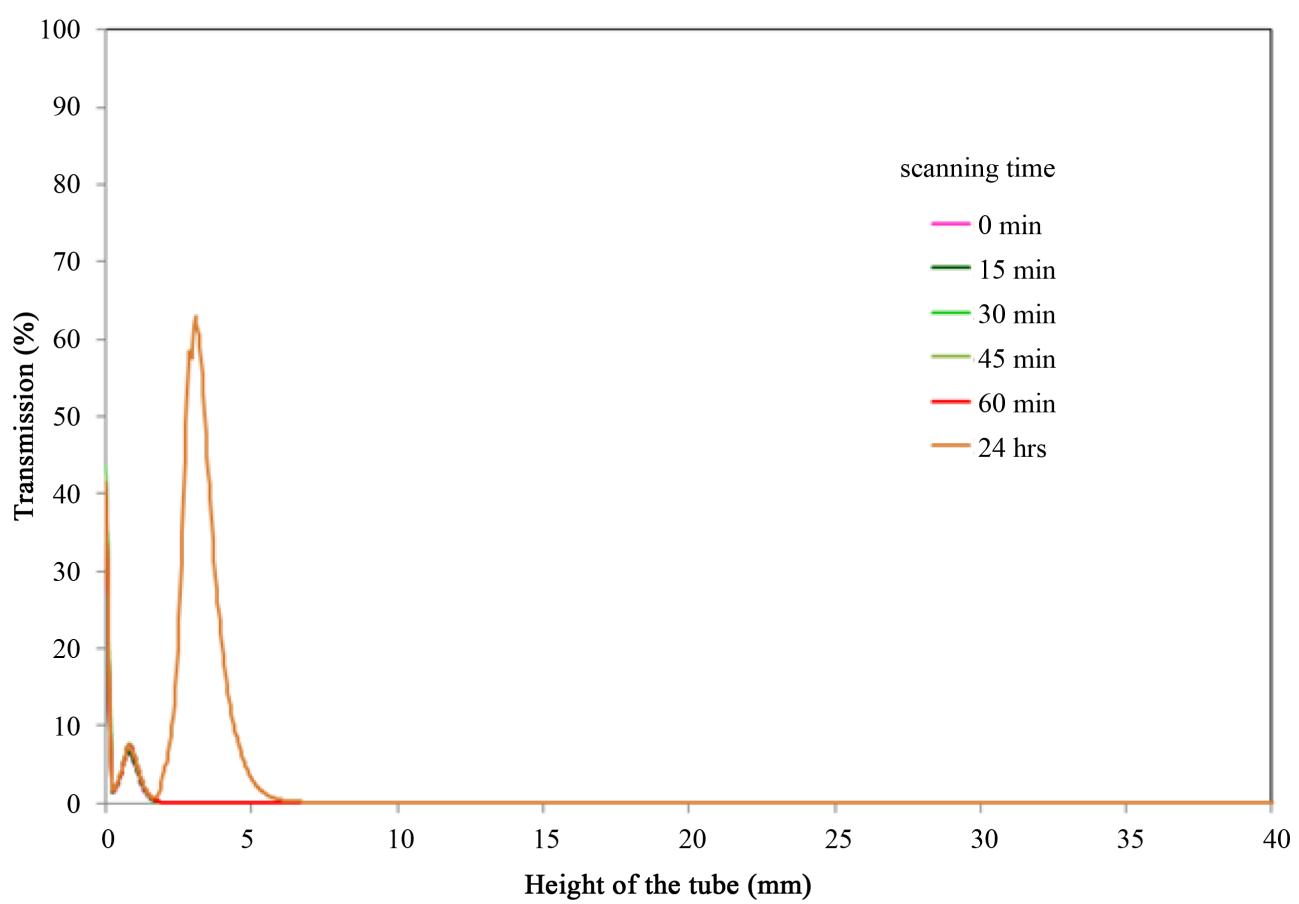

(a)

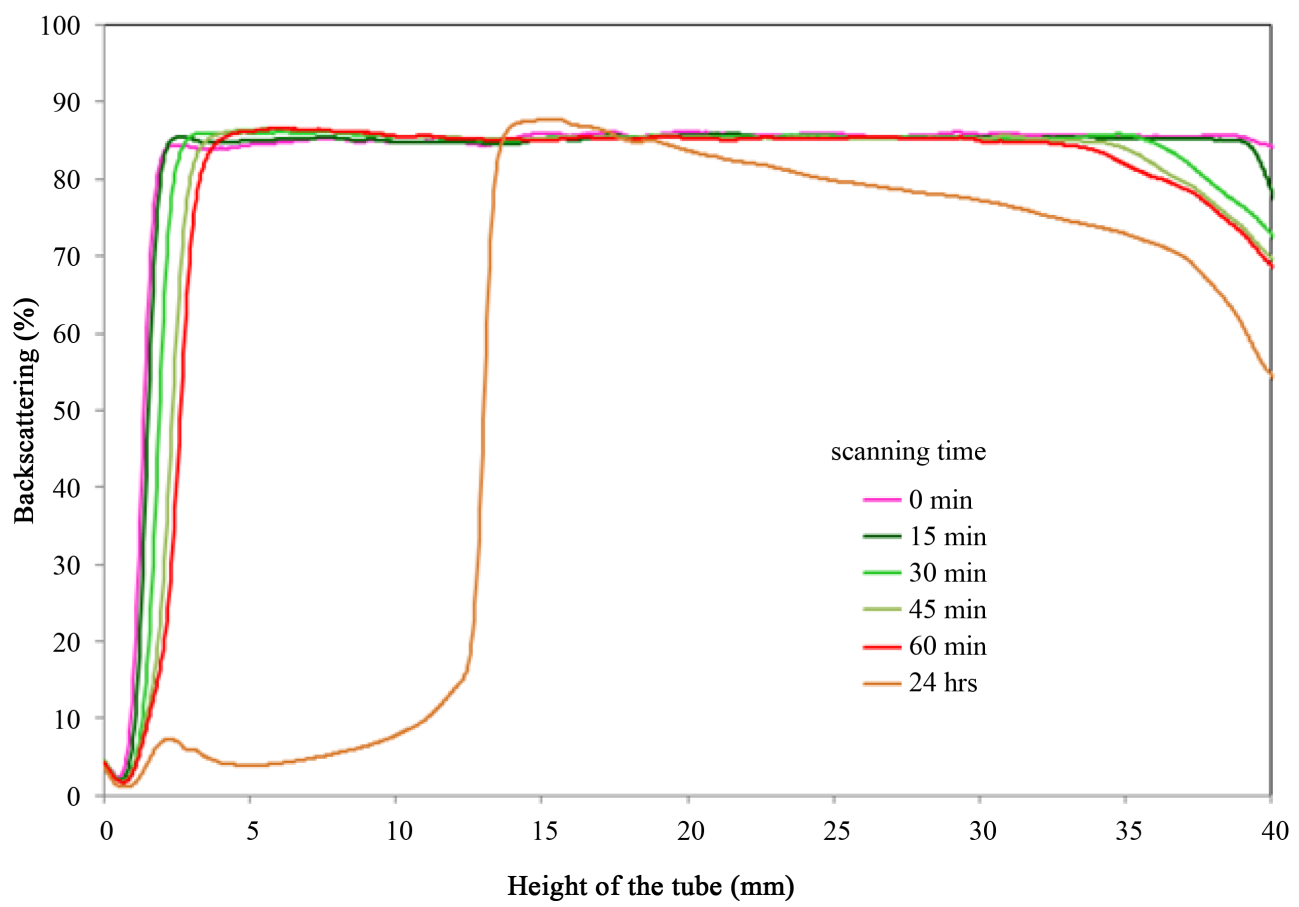

(b)

Figure 6. Emulsion of toluene and water ( $0.15 \mathrm{~g} / \mathrm{L}$ of RLe). Light transmission (a) and backscattering (b) profiles of the emulsion in function of time.

different polarities and structures using just a small amount of surfactant. Furthermore, the highest interfacial tension reduction were observed in the systems with linear alkanes.

In a more hydrophilic system, such as castor oil and methyl-metacrylate, the ramnolipid decreases slightly the interfacial tension. Comparatively, RLe was more effective than SDS (interfacial tension reduction per weight of surfactant), suggesting that the RLe can be used in various processes (especially those required to reduce the in- 
Table 1. Interfacial tension hydrocarbon/water solution.

\begin{tabular}{|c|c|c|c|c|}
\hline \multirow{2}{*}{ Hydrocarbons } & \multicolumn{3}{|c|}{ Surfactant } & \multirow[b]{2}{*}{ SDS $(10 \mathrm{~g} / \mathrm{L})$} \\
\hline & Water & RLe (0.15 g/L) & RLe (1 g/L) & \\
\hline Toluene & $32.50 \pm 0.37$ & $3.95 \pm 0.47$ & - & $2.63 \pm 0.14$ \\
\hline n-heptane & $43.23 \pm 1.35$ & $3.54 \pm 0.16$ & - & $1.33 \pm 0.03$ \\
\hline Octane & $47.17 \pm 0.13$ & $1.11 \pm 0.03$ & - & $1.31 \pm 0.05$ \\
\hline Hexadecane & $47.95 \pm 0.87$ & $0.70 \pm 0.11$ & - & $1.85 \pm 0.89$ \\
\hline Methyl metacrilate & $11.64 \pm 1.01$ & $9.21 \pm 0.18$ & $5.22 \pm 0.06$ & $6.78 \pm 0.17$ \\
\hline Castor oil & $18.75 \pm 0.32$ & $10.27 \pm 0.65$ & $7.60 \pm 1.3$ & $9.54 \pm 0.86$ \\
\hline Petroleum & $21.21 \pm 0.08$ & $1.40 \pm 0.15$ & - & $7.19 \pm 3.12$ \\
\hline
\end{tabular}

terfacial tension between water and an organic phase), and can replace the petrochemical surfactants. Another favorable point of rhamnolipids is that they are biodegradable, while SDS compounds have low biodegradability [33] [34].

The SDS and RLe reduced the interfacial tension between crude oil and water as seen in Table 1. A large reduction in interfacial tension between water and oil $21 \mathrm{mN} / \mathrm{m}$ (without surfactant) to $1 \mathrm{mN} / \mathrm{m}$ (with $0.15 \mathrm{~g} / \mathrm{L}$ RLe) can be achieved with rhamnolipids, while a less significant value ( $7 \mathrm{mN} / \mathrm{m}$ ) can be achieved with SDS (10 $\mathrm{g} / \mathrm{L})$.

Figures 6-11 show the emulsion stability behavior of emulsions of water solutions with $0.15 \mathrm{~g} / \mathrm{L}$ of RLe and the hydrocarbons which were evaluated for interfacial tension. This characterization is important to evaluate how the RLe can assist in the stabilization of emulsions with different types of hydrocarbons.

Emulsions are not stable and are subject to various phenomena, such as flocculation, Otswald ripening (diffusional degradation) and coalescence [35]-[37]. They are stabilized by conventional emulsifiers including surfactants, which form a layer around the droplets of the emulsion and therefore reduce the interfacial energy and provide a barrier to coalescence [35]. Rhamnolipids are able to stabilize water emulsions containing benzene, soybean oil and kerosene [24]. Generally, articles that deal with processes of stability and emulsification used the emulsification index E24 as measurement [24] [38] which takes into account only droplet coalescence to the interface, increasing the volume of the separated phase. Thus, for accuracy, laser profiling was used to analyze some phenomena related to the instability of emulsions [37].

Emulsions were prepared in a 50/50 water:hydrocarbon ratio, $0.15 \mathrm{~g} / \mathrm{L}$ of RLe was dissolved in water. Figures 6-11 show the emulsions light transmission and backscattering profiles. During the first hour, none of these emulsions showed changes in the transmission, but an increase in transmission (Figure 6(a), Figure 8(a), Figure 10(a) and Figure 11(a)) and even a clear phase at the bottom could be observed in some experiments (Figure 7(a) and Figure 9(a)).

Through the backscattering is possible to identify different phenomena that occur in emulsions, such as: a clarification, creaming, flocculation and coalescence [19] [37]. Figure 6(b) shows the backscattering profile of the toluene in water emulsion. The emulsion remains stable up to 1 hour after preparation, however after 24 hours it is possible to observe a clarification at the top of the tube and a water phase at the bottom.

Figure 7(b) shows the backscaterring profile of the n-heptane in water emulsion, it is possible to observe a fast demulsification process, and as a consequence of the coalescence a clear water phase is present at the bottom of tube. Figure 7(b) shows emulsions with droplets merging and generating larger droplets, which results in clotting and subsequent coalescence.

The backscattering of the octane emulsion (Figure 8(b)) showed different characteristics from the others. This emulsion remained stable up to 1 hour, but after 24 hours it underwent clarification of the water phase and creaming (increase of concentration of dispersed phase). The emulsion octane was not stable, and after 24 hours more than $80 \%$ of the total bottle showed clarification with creaming.

The hexadecane emulsion (Figure 9(b)) was stable for 1 hour. After 24 hours, 35\% of the bottle presented a clarification process at bottom and in a less extent at the top. The emulsion methyl methacrylate (Figure 10(b)) was the only that showed a good stability even after 24 hours with no visible phase separation, however laser profiling measurements showed changes in the emulsion namely clarification at the bottom due to creaming and 


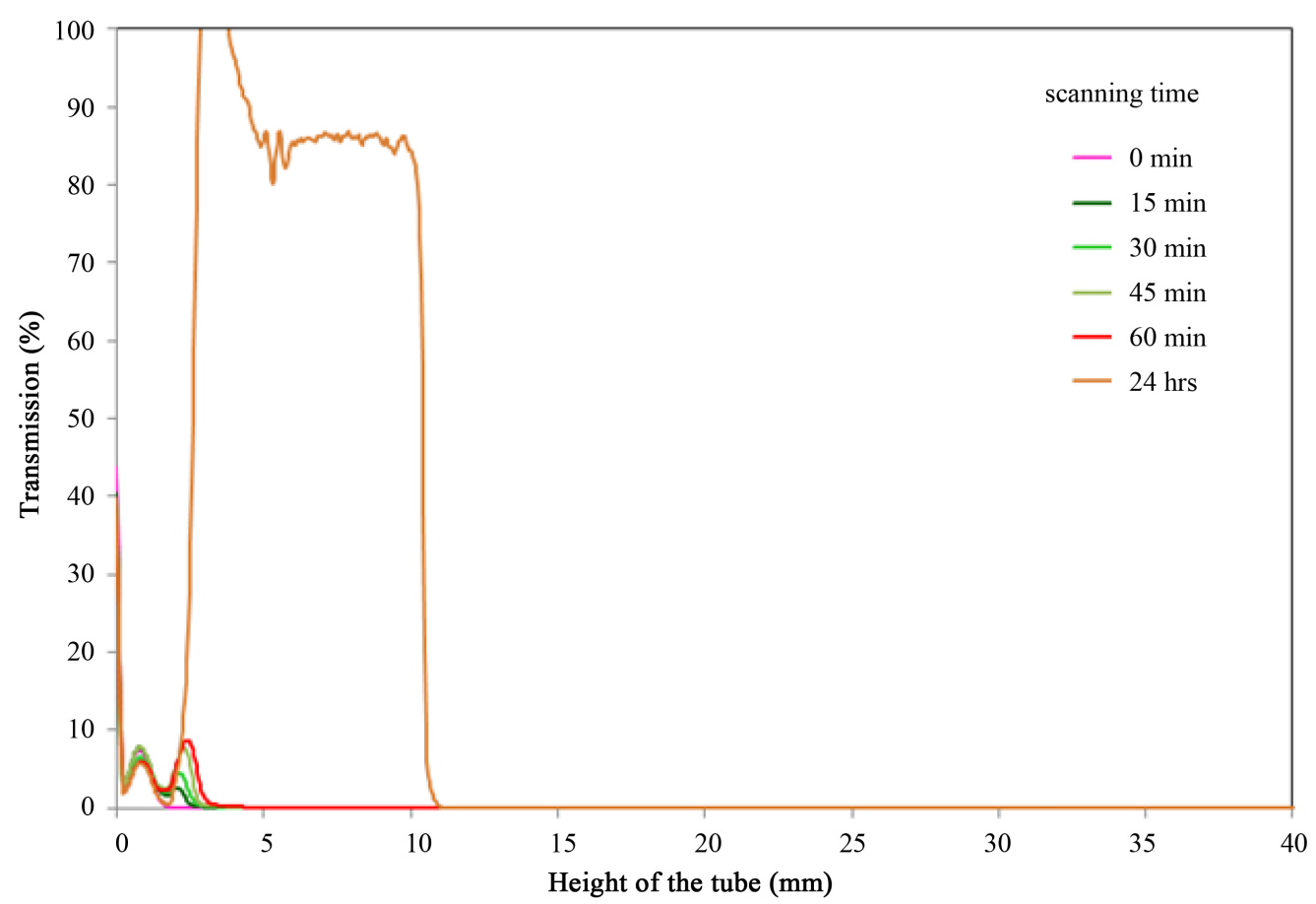

(a)

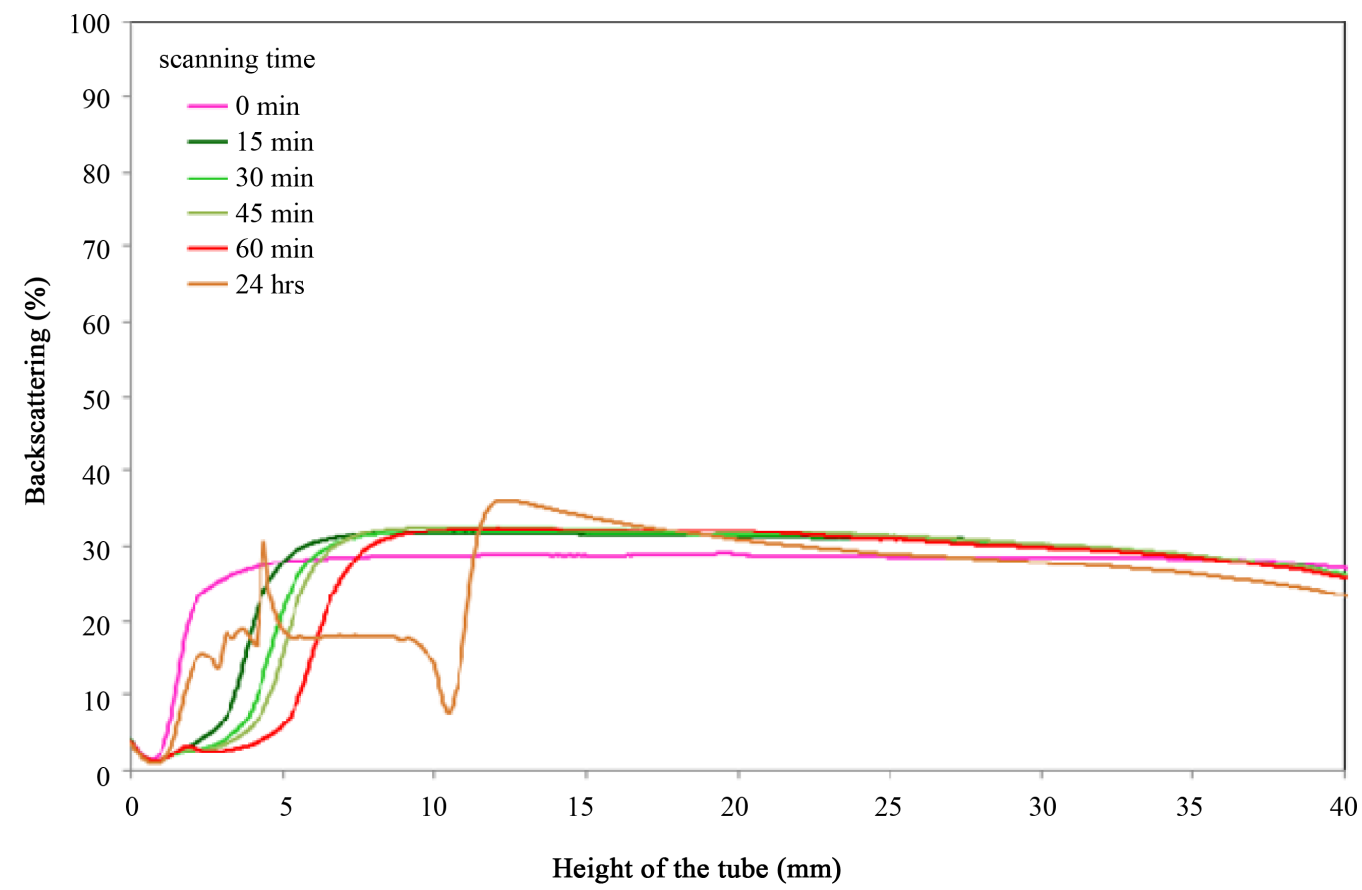

(b)

Figure 7. Emulsion of n-heptane and water ( $0.15 \mathrm{~g} / \mathrm{L}$ of RLe). Light transmission (a) and backscattering (b) profiles of the emulsion in function of time.

significant changes in the droplet size, indicated by significant changes in the backscattering profile. Thus, RLe in concentration of $0.15 \mathrm{~g} / \mathrm{L}$ is able to maintain a good stability of methyl methacrylate/water emulsions. This is not suprisingly because the rhamnolipid was not able to reduce water/MMA interfacial tension significantly. The size of the micelles formed in the emulsions methyl methacrylate was between $80 \mathrm{~nm}$ and $90 \mathrm{~nm}$ in 24 hours. 


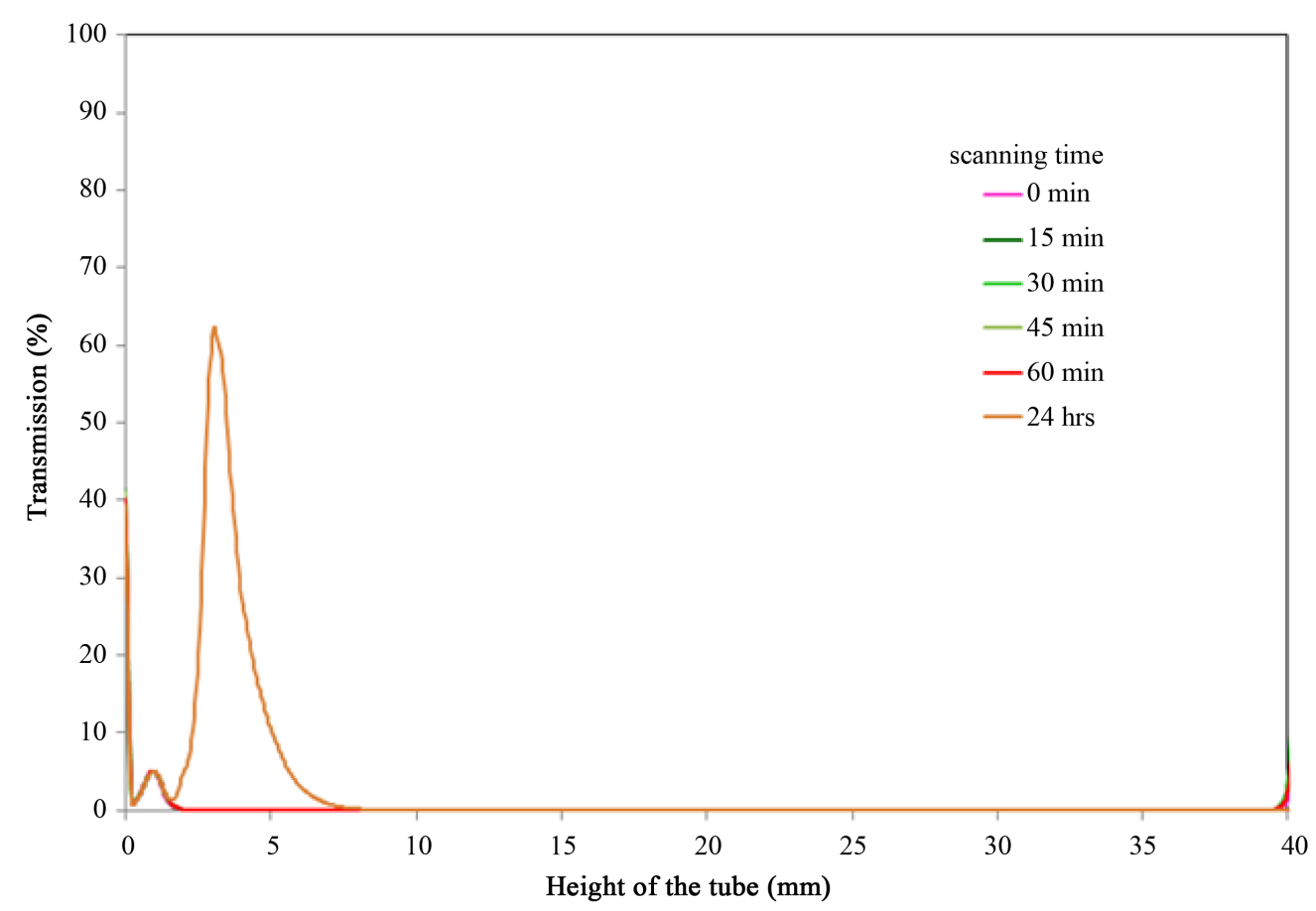

(a)

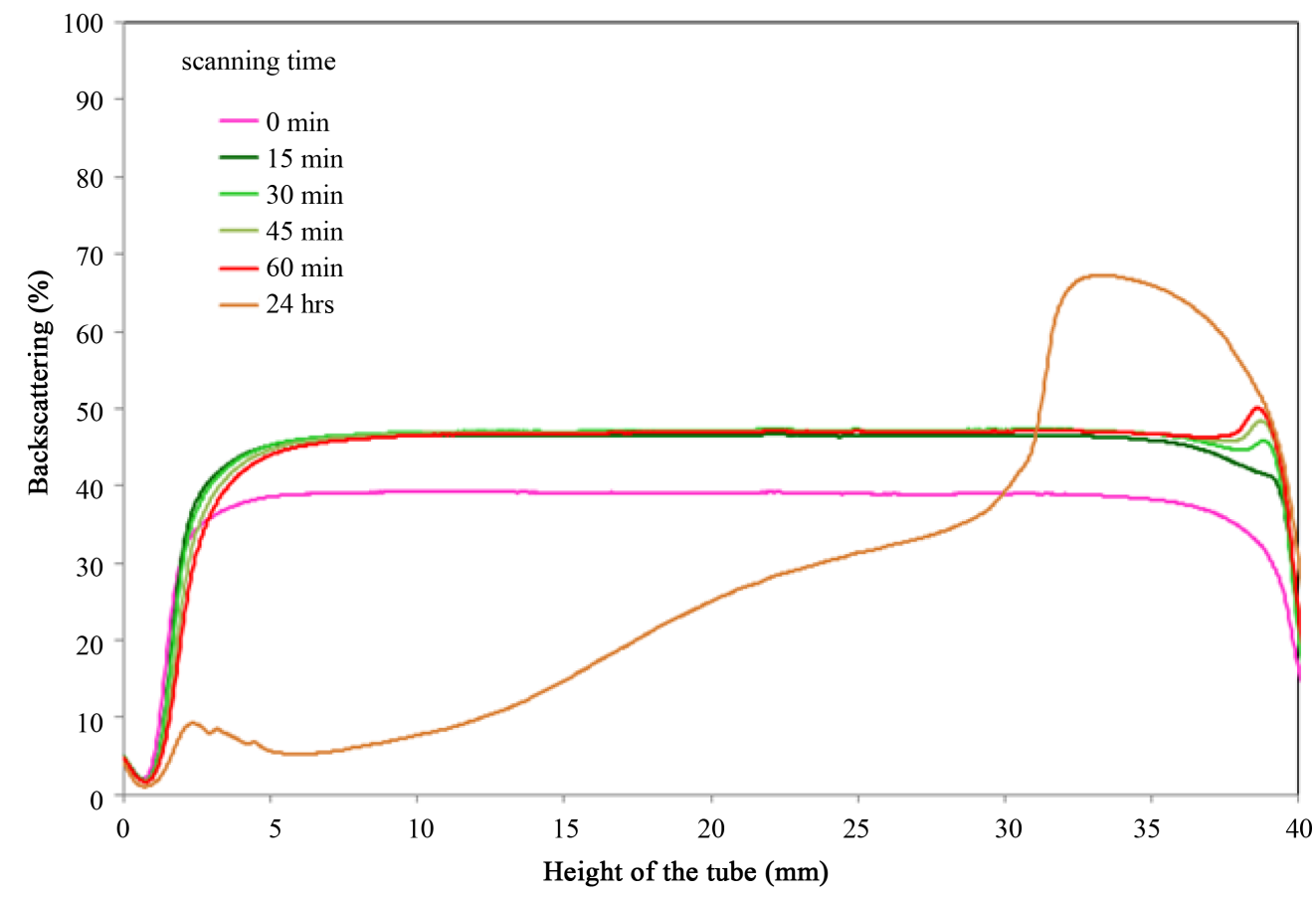

(b)

Figure 8. Emulsion of octane and water ( $0.15 \mathrm{~g} / \mathrm{L}$ of RLe). Light transmission (a) and backscattering (b) profiles of the emulsion in function of time.

The profile of the backscattering emulsions can be classified by the degree of stability as follows: emulsion methyl methacrylate (Figure 10(b)) > emulsions of castor oil (Figure 11(b)) > emulsion n-heptane (Figure 7(b)) > emulsion toluene (Figure 6(b)) > emulsion hexadecane (Figure 9(b)) > octane emulsion (Figure 8(b)). This classification can be correlated with the ability of the surfactant RLe to act as an emulsion stabilizer. How- 


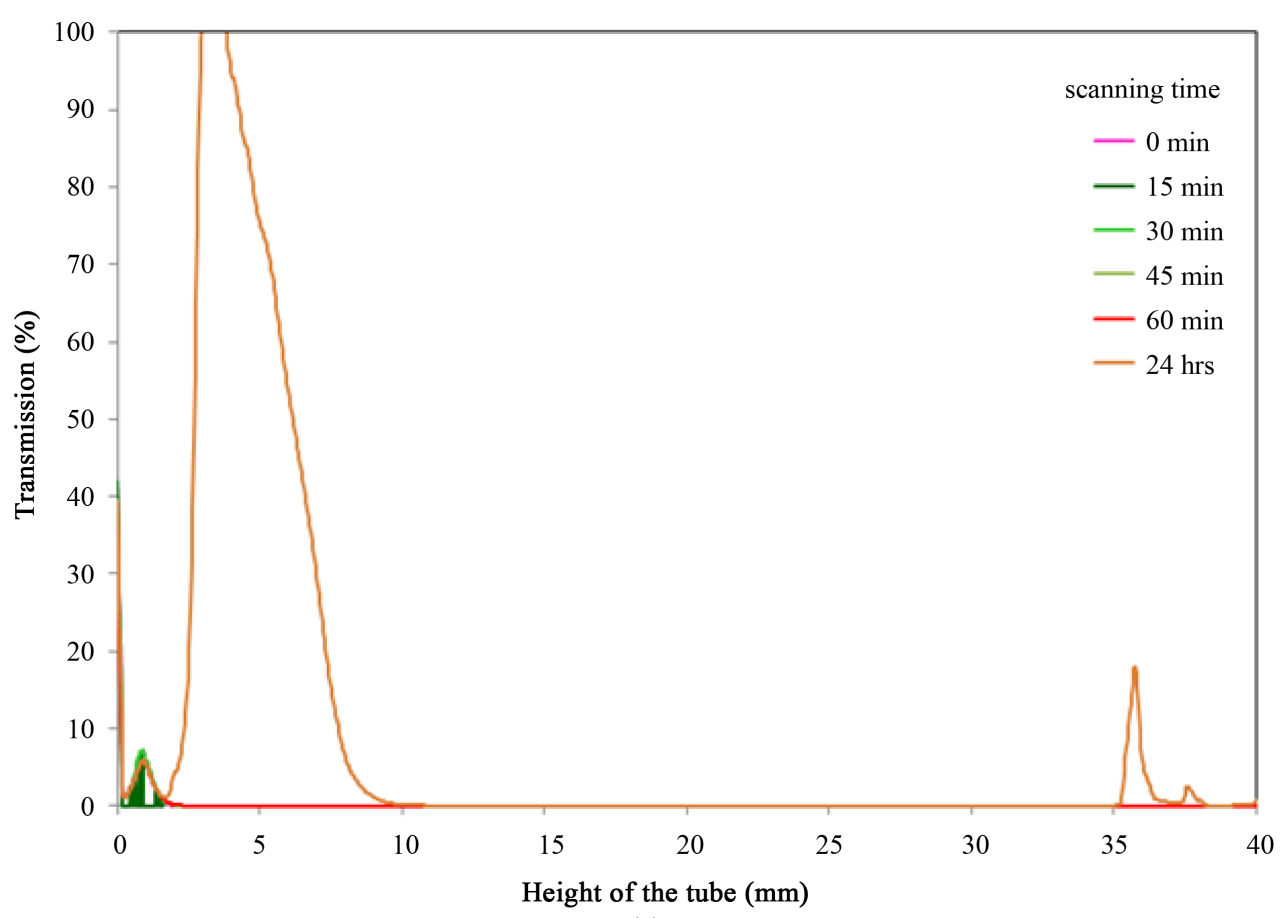

(a)

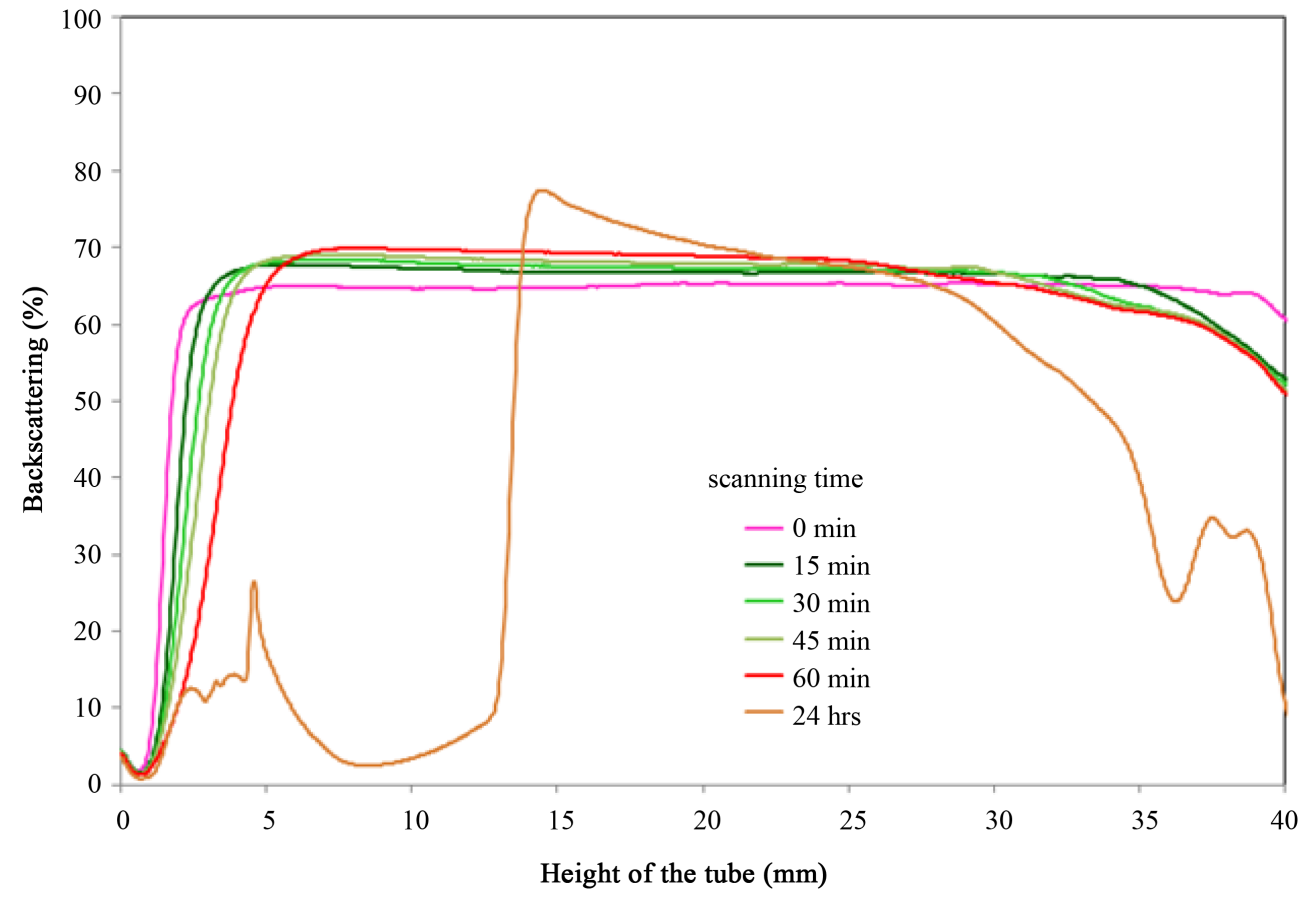

(b)

Figure 9. Emulsion of hexadecane and water ( $0.15 \mathrm{~g} / \mathrm{L}$ of RLe). Light transmission (a) and backscattering (b) profiles of the emulsion in function of time.

ever, for emulsions with octane, the use of RLe is not recommended.

\section{Conclusions}

Rhamnolipids are thermostable surfactants. Two heating treatments at a temperature of $80^{\circ} \mathrm{C}$ for a period of one 


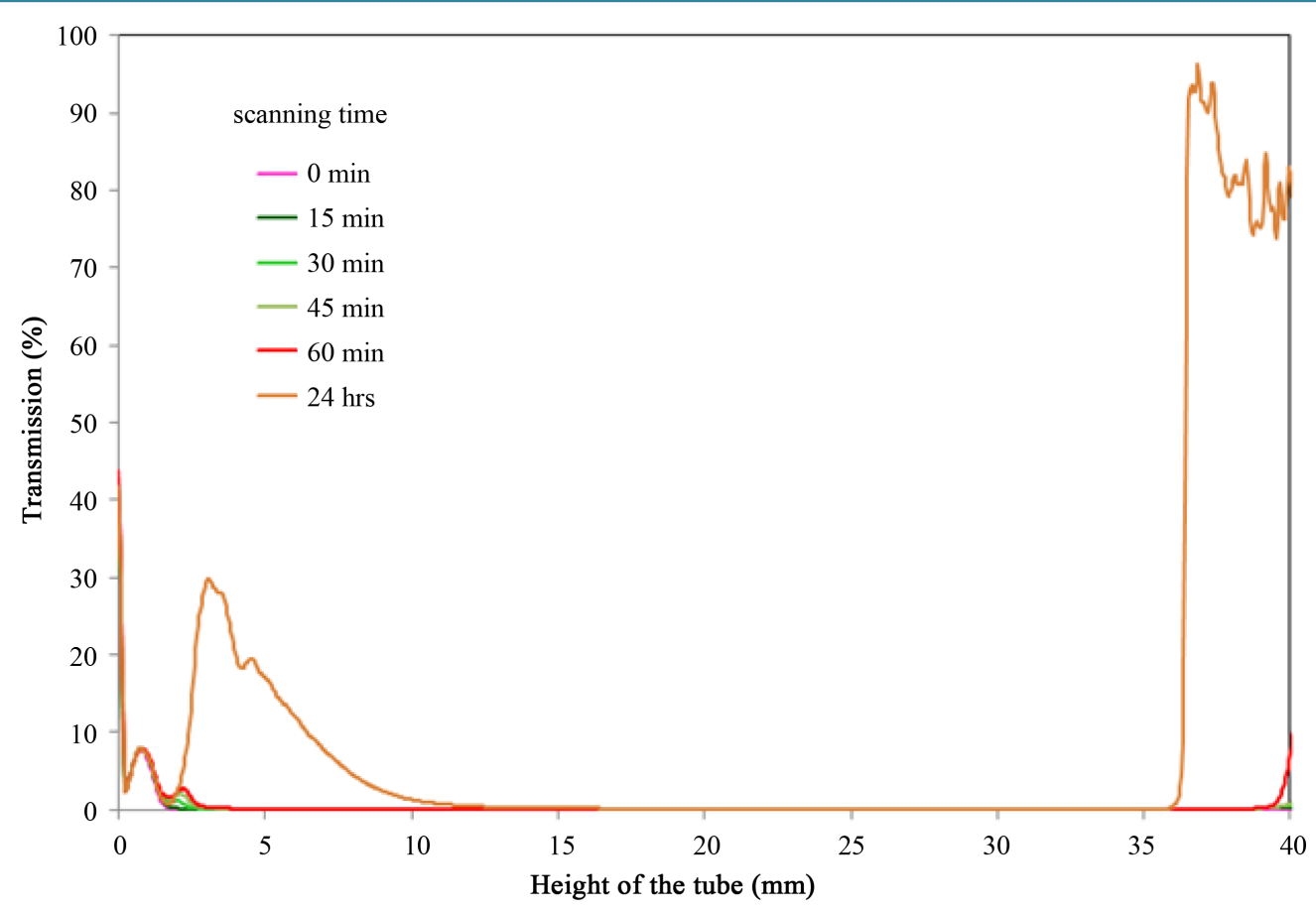

(a)

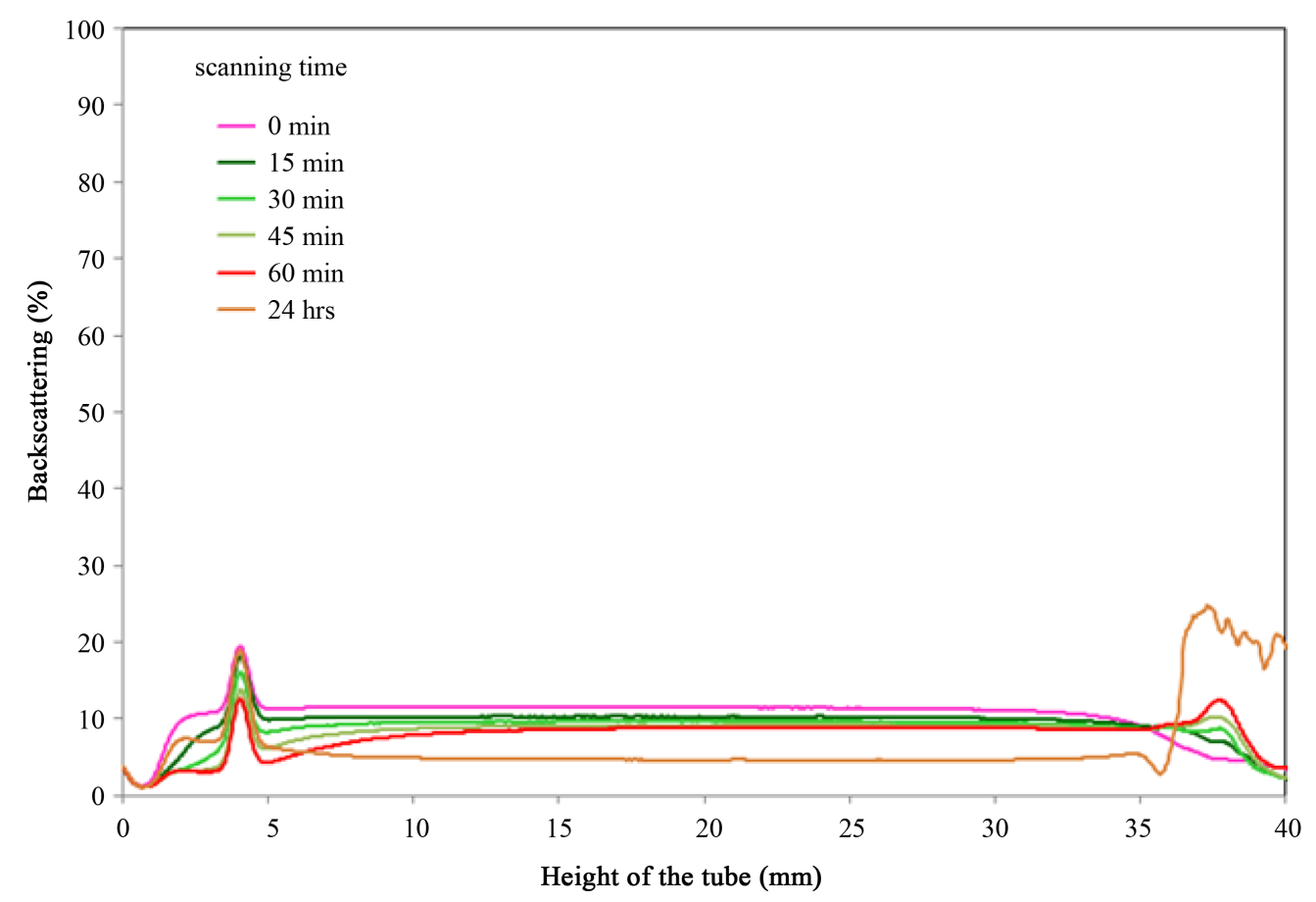

(b)

Figure 10. Emulsion of methy metacrilate and water (0.15 g/L of RLe). Light transmission (a) and backscattering (b) profiles of the emulsion in function of time.

hour did not affect the ability of the rhamnolipid extract to reduce the interfacial tension. This information is important to demonstrate that the extract can be reused in systems that require the use of relatively high temperatures and $\mathrm{pH}$ can interfere in the critical micellar concentration and size of the rhamnolipid micelle.

The emulsion stability did not follow the trend suggested by the interfacial tension. Emulsions of methyl 


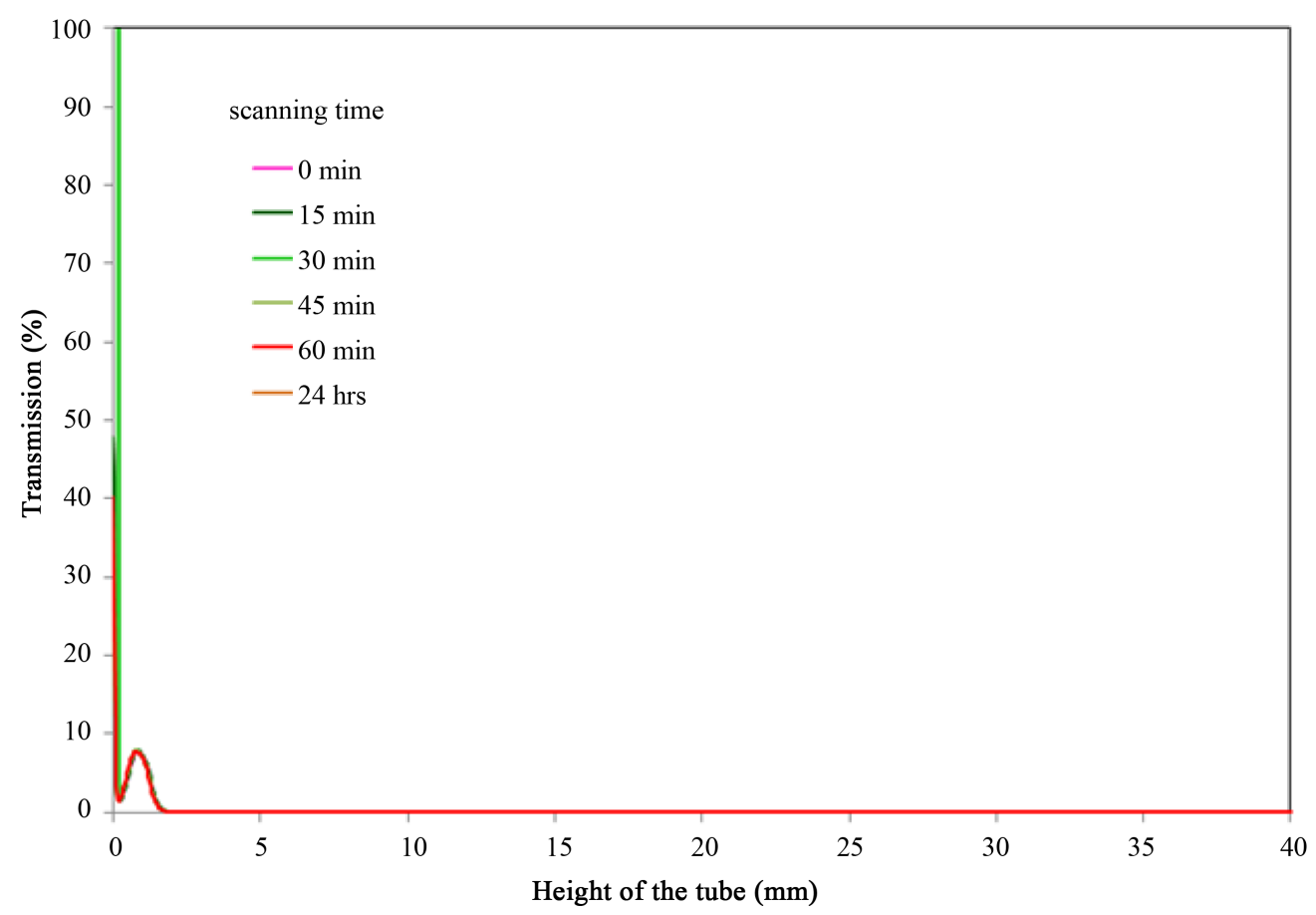

(a)

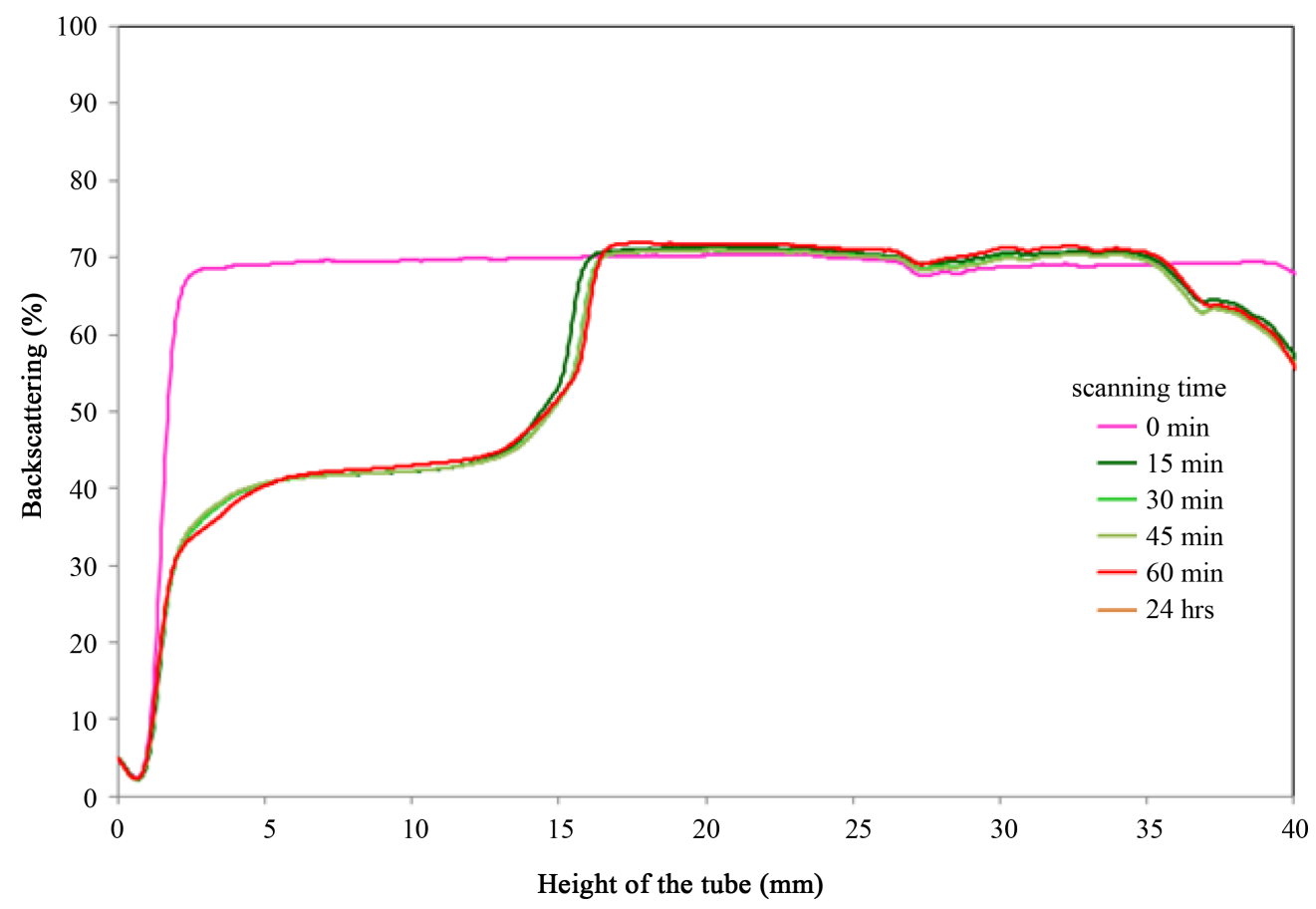

(b)

Figure 11. Emulsion of castor oil and water ( $0.15 \mathrm{~g} / \mathrm{L}$ of RLe). Light transmission (a) and backscattering (b) profiles of the emulsion in function of time.

methacrylate and water containing rhamnolipid are stable, nevertheless the reduction in the interfacial tension in this system due to rhamnolipid is very modest emphasizing, that to estimate the ability of a surfactant to stabilize an emulsion it is necessary to use a different parameter. Thus, this paper proposes the possibility of using rhamnolipids in processes of nano/micropheres formulations of poly-methyl methacrylate that require using biosur- 
factants.

\section{Acknowledgements}

The authors wish to thank to Prof. Denise Freire for donating the strain of Pseudomonas. Brigida Orioli and Davyson Moreira helpful discussions and suggestions. This work was supported by the Conselho Nacional de Desenvolvimento Científico e Tecnológico (CNPq), Fundação Carlos Chagas Filho de Amparo à Pesquisa do Estado do Rio de Janeiro (FAPERJ), Coordenação de Aperfeiçoamento de Pessoal do Ensino Superior (CAPES).

\section{References}

[1] Soberón-Chávez, G., Lépine, F. and Dézie, E. (2005) Production of Rhamnolipids by Pseudomonas aeruginosa. Applied Microbiology and Biotechnology, 68, 718-725. http://dx.doi.org/10.1007/s00253-005-0150-3

[2] Gudiña, E.J., Rodrigues, A.I., Alves, E., Domingues, M.R., Teixeira, J.A. and Rodrigues, L.R. (2014) Bioconversion of Agroindustrial By-Products in Rhamnolipids toward Applications in Enhanced Oil Recovery and Bioremediation. Bioresource Technology, 177C, 87-93. http://dx.doi.org/10.1016/j.biortech.2014.11.069

[3] Maier, R.M. and Soberón-Chávez, G. (2000) Pseudomonas aeruginosa Rhamnolipids: Biosynthesis and Potential Applications. Applied Microbiology and Biotechnology, 54, 625-633. http://dx.doi.org/10.1007/s002530000443

[4] Stanghellini, M.E. and Miller, R.M. (1997) Biosurfactants: Their Identity and Potential Efficacy in the Biological Control of Zoosporic Plant Pathogens. Plant Disease, 81, 4-12. http://dx.doi.org/10.1094/PDIS.1997.81.1.4

[5] Guo, Y.P., Hu, Y.Y., Gu, R.R. and Lin, H. (2009) Characterization and Micellization of Rhamnolipidic Fractions and Crude Extracts Produced by Pseudomonas aeruginosa Mutant MIG-N146. Journal of Colloid and Interface Science, 331, 356-363. http://dx.doi.org/doi:10.1016/j.jcis.2008.11.039

[6] Déziel, E., Lépine, F., Milot, S. and Villemur, R. (2003) rhlA Is Required for the Production of a Novel Biosurfactant Promoting Swarming Motility in Pseudomonas aeruginosa: 3-(3-hydroxyalkanoyloxy) Alkanoic Acids (HAAs), the Precursors of Rhamnolipids. Microbiology, 149, 2005-2013. http://dx.doi.org/doi:10.1099/mic.0.26154-0

[7] Abdel-Mawgoud, A.M., Lépine, F. and Déziel, E. (2010) Rhamnolipids: Diversity of Structures, Microbial Origins and Roles. Applied Microbiology and Biotechnology, 86, 1323-1336. http://dx.doi.org/doi:10.1007/s00253-010-2498-2

[8] Samadi, N., Abadian, N., Ahmadkhaniha, R., Amini, F., Dalili, D., Rastkari, N., Safaripour, E. and Mohseni, F.A. (2012) Structural Characterization and Surface Activities of Biogenic Rhamnolipid Surfactants from Pseudomonas aeruginosa Isolate MN1 and Synergistic Effects against Methicillin-Resistant Staphylococcus aureus. Folia Microbiologica (Praha), 57, 501-8. http://dx.doi.org/doi:10.1007/s12223-012-0164-z

[9] Mata-Sandoval, J.C., Karns, J. and Torrents, A. (1999) High-Performance Liquid Chromatography Method for the Characterization of Rhamnolipid Mixtures Produced by Pseudomonas aeruginosa UG2 on Corn Oil. Journal of Chromatography A, 864, 211-220. http://dx.doi.org/doi:10.1016/S0021-9673(99)00979-6

[10] Liu, Y., Zhong, H., Liu, Z., Jiang, Y., Tan, F., Zeng, G., Lai, M. and He, Y. (2014) Purification and Characterization of the Biosurfactant Rhamnolipid. Se Pu, 32, 248-255.

[11] Déziel, E., Lépine, F., Dennie, D., Boismenu, D., Mamer, O.A. and Villemur, R. (1999) Liquid Chromatography/Mass Spectrometry Analysis of Mixtures of Rhamnolipids Produced by Pseudomonas aeruginosa Strain 57RP Grown on Mannitol or Naphthalene. Biochimica et Biophysica Acta (BBA) - Molecular and Cell Biology of Lipids, 1440, $244-252$. http://dx.doi.org/doi:10.1016/S1388-1981(99)00129-8

[12] Dar, A.A., Rather, G.M., Ghosh, S. and Das, A.R. (2008) Micellization and Interfacial Behavior of Binary and Ternary Mixtures of Model Cationic and Nonionic Surfactants in Aqueous NaCl Medium. Journal of Colloid and Interface Science, 322, 572-581. http://dx.doi.org/10.1016/j.jcis.2008.03.022

[13] Zhang, Y.M., Maier, W.J. and Miller, R.M. (1997) Effect of Rhamnolipids on the Dissolution, Bioavailability, and Biodegradation of Phenanthrene. Environmental Science Technology, 31, 2211-2217. http://dx.doi.org/10.1021/es960687g

[14] Shin, K.H., Kim, K.W. and Seagren, E.A. (2004) Combined Effects of pH and Biosurfactant Addition on Solubilization and Biodegradation of Phenanthrene. Applied Microbiology and Biotechnology, 65, 336-343. http://dx.doi.org/10.1007/s00253-004-1561-2

[15] Itoh, S. and Suzuki, T. (1972) Effect of Rhamnolipids on Growth of Pseudomonas aeruginosa Mutant Deficient in n-Paraffin-Utilizing Ability. Agricultural and Biological Chemistry, 36, 2233-2235. http://dx.doi.org/10.1271/bbb1961.36.2233

[16] Koch, A.K., Käppeli, O., Fiechter, A. and Reiser, J. (1991) Hydrocarbon Assimilation and Biosurfactant Production in Pseudomonas aeruginosa Mutants. Journal of Bacteriology, 173, 4212-4219. 
[17] Kronemberger, F.D., Santa-Anna, L., Fernandes, A., Menezes, R., Borges, C. and Freire, D. (2008) Oxygen Controlled Biosurfactant Production in a Bench Scale Bioreactor. Applied Biochemistry and Biotechnology, 147, 33-45. http://dx.doi.org/10.1007/s12010-007-8057-3

[18] Dubois, M., Gilles, K., Hamilton, J.K., Rebers, P.A. and Smith, F. (1951) A Colorimetric Method for the Determination of Sugars. Nature, 168, 167. http://dx.doi.org/10.1038/168167a0

[19] Mendes, A.N., Hubber, I., Siqueira, M., Barbosa, G.M., de Lima Moreira, D., Holandino, C., Pinto, J.C. and Nele, M. (2012) Preparation and Cytotoxicity of Poly(Methyl Methacrylate) Nanoparticles for Drug Encapsulation. Macromolecular Symposia, 319, 34-40. http://dx.doi.org/10.1002/masy.201100248

[20] Saien, J. and Akbari, S. (2006) Interfacial Tension of Toluene + Water + Sodium Dodecyl Sulfate from (20 to 50) ${ }^{\circ} \mathrm{C}$ and $\mathrm{pH}$ between 4 and 9. Journal of Chemical \& Engineering Data, 51, 1832-1835.

http://dx.doi.org/10.1021/je060204g

[21] Ilori, M.O., Amobi, C.J. and Odocha, A.C. (2005) Factors Affecting Biosurfactant Production by Oil Degrading Aeromonas spp. Isolated from a Tropical Environment. Chemosphere, 61, 985-992. http://dx.doi.org/10.1016/j.chemosphere.2005.03.066

[22] Inakollu, S., Hung, H.C. and Shreve, G.S. (2004) Biosurfactant Enhancement of Microbial Degradation of Various Structural Classes of Hydrocarbon in Mixed Waste Systems. Environmental Engineering Science, 21, 463-469. http://dx.doi.org/10.1089/1092875041358467

[23] Lebrón-Paler, A., Pemberton, J.E., Becker, B.A., Otto, W.H., Larive, C.K. and Maier, R.M. (2006) Determination of the Acid Dissociation Constant of the Biosurfactant Monorhamnolipid in Aqueous Solution by Potentiometric and Spectroscopic Methods. Analytical Chemistry, 78, 7649-7658. http://dx.doi.org/10.1021/ac0608826

[24] Lovaglio, R.B., dos Santos, F.J., Jafelicci-Junior, M. and Contiero, J. (2011) Rhamnolipid Emulsifying Activity and Emulsion Stability: pH Rules. Colloids and Surfaces B: Biointerfaces, 85, 301-305. http://dx.doi.org/10.1016/j.colsurfb.2011.03.001

[25] Sánchez, M., Aranda, F.J., Espuny, M.J. and Marqués, A. (2007) Aggregation Behavior of a Dirhamnolipid Biosurfactant Secreted by Pseudomonas aeruginosa in Aqueous Media. Journal of Colloid and Interface Science, 307, 246-253. http://dx.doi.org/10.1016/j.jcis.2006.11.041

[26] Pornsunthorntawee, O., Chavadej, S. and Rujiravanit, R. (2011) Characterization and Encapsulation Efficiency of Rhamnolipid Vesicles with Cholesterol Addition. Journal of Bioscience and Bioengineering, 112, 102-106. http://dx.doi.org/10.1016/j.jbiosc.2011.03.009

[27] Pornsunthorntawee, O., Chavadej, S. and Rujiravanit, R. (2009) Solution Properties and Vesicle Formation of Rhamnolipid Biosurfactants Produced by Pseudomonas aeruginosa SP4. Colloids and Surfaces B: Biointerfaces, 72, 6-15. http://dx.doi.org/10.1016/j.colsurfb.2009.03.006

[28] Bai, G., Brusseau, M.L. and Miller, R.M. (1997) Influence of a Rhamnolipid Biosurfactant on the Transport of Bacteria through a Sandy Soil. Applied and Environmental Microbiology, 63, 1866-1873.

[29] Ishigami, Y., Gama, Y., Ishii, F. and Choi, Y.K. (1993) Colloid Chemical Effect of Polar Head Moieties of a Rhamnolipid-Type Biosurfactant. Langmuir, 9, 1634-1636. http://dx.doi.org/10.1021/la00031a006

[30] Helvaci, S.S., Peker, S. and Özdemir, G. (2004) Effect of Electrolytes on the Surface Behavior of Rhamnolipids R1 and R2. Colloids and Surfaces B: Biointerfaces, 35, 225-233. http://dx.doi.org/10.1016/j.colsurfb.2004.01.001

[31] Nitschke, M., Costa, S.G.V.A.O. and Contiero, J. (2005) Rhamnolipid Surfactants: An Update on the General Aspects of These Remarkable Biomolecules. Biotechnology Progress, 21, 1593-1600. http://dx.doi.org/10.1021/bp050239p

[32] Wang, Q., Fang, X., Bai, B., Liang, X., Shuler, P.J., Goddard, W.A., et al. (2007) Engineering Bacteria for Production of Rhamnolipid as an Agent for Enhanced Oil Recovery. Biotechnol Bioeng, 98, 842-853. http://dx.doi.org/10.1002/bit.21462

[33] Nguyen, T.T., Edelen, A., Neighbors, B. and Sabatini, D.A. (2010) Biocompatible Lecithin-Based Microemulsions with Rhamnolipid and Sophorolipid Biosurfactants: Formulation and Potential Applications. Journal of Colloid and Interface Science, 348, 498-504. http://dx.doi.org/10.1016/j.jcis.2010.04.053

[34] Urum, K., Grigson, S., Pekdemir, T. and McMenamy, S. (2006) A Comparison of the Efficiency of Different Surfactants for Removal of Crude Oil from Contaminated Soils. Chemosphere, 62, 1403-1410. http://dx.doi.org/10.1016/j.chemosphere.2005.05.016

[35] Patel, P.A., Chaulang, G.M., Akolkotkar, A., Mutha, S.S., Hardikar, S.R. and Bhosale, A.V. (2008) Self Emulsifying Drug Delivery System: A Review. Research Journal of Pharmacy and Technology, 1, 313-323.

[36] Schork, F.J., Luo, Y., Smulders, W., Russum, J.P., Butté, A. and Fontenot, K. (2005) Miniemulsion Polymerization. Advances in Polymer Science, 175, 129-255. http://dx.doi.org/10.1016/S0079-6700(02)00010-2

[37] Mengual, O., Meunier, G., Cayre, I., Puech, K. and Snabre, P. (1999) Characterisation of Instability of Concentrated 
Dispersions by a New Optical Analyser: The TURBISCAN MA 1000. Colloids and Surfaces A: Physicochemical and Engineering Aspects, 152, 111-123. http://dx.doi.org/10.1016/S0927-7757(98)00680-3

[38] Costa, S.G.V.A.O., Nitschke, M., Lépine, F., Déziel, E. and Contiero, J. (2010) Structure, Properties and Applications of Rhamnolipids Produced by Pseudomonas aeruginosa L2-1 from Cassava Wastewater. Process Biochemistry, 45, 1511-1516. http://dx.doi.org/10.1016/j.procbio.2010.05.033 
Scientific Research Publishing (SCIRP) is one of the largest Open Access journal publishers. It is currently publishing more than 200 open access, online, peer-reviewed journals covering a wide range of academic disciplines. SCIRP serves the worldwide academic communities and contributes to the progress and application of science with its publication.

Other selected journals from SCIRP are listed as below. Submit your manuscript to us via either submit@scirp.org or Online Submission Portal.
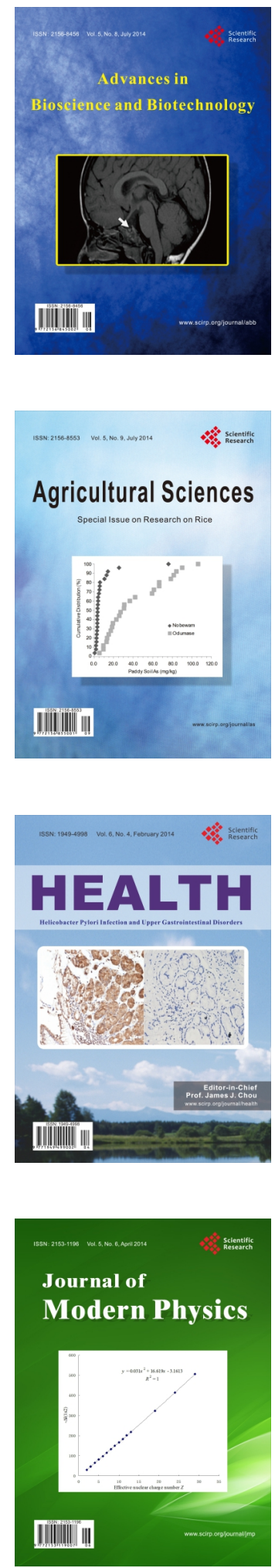
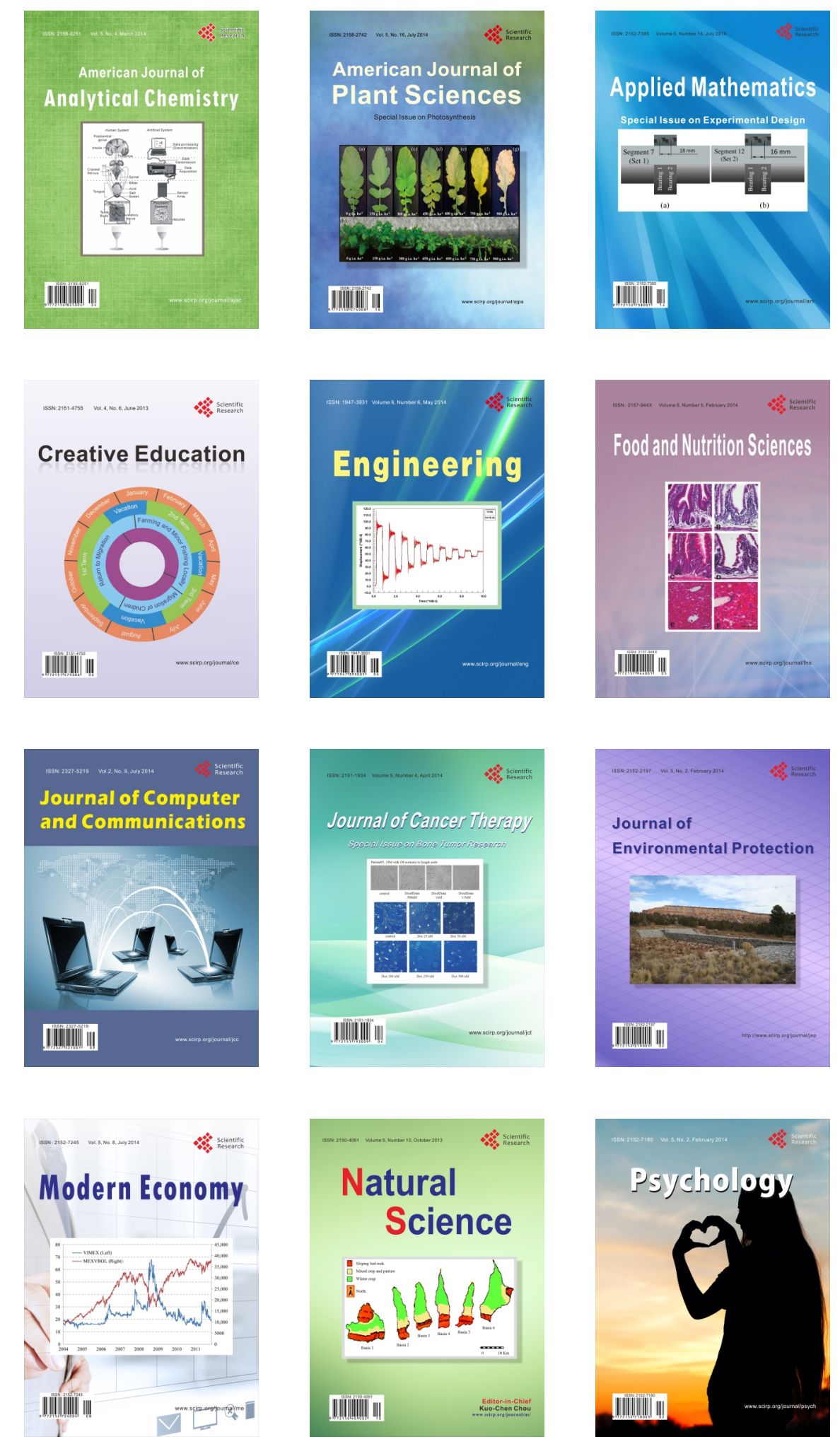